\title{
REVIEW
}

Open Access

\section{Clinical and histological sequelae of surgical complications in horizontal guided bone regeneration: a systematic review and proposal for management}

\author{
John Rong Hao Tay ${ }^{1,2}$, Xiaotong Jacinta Lu', Wei Ming Clement Lai ${ }^{3}$ and Jia-Hui Fu ${ }^{1 *}$ (D)
}

\begin{abstract}
It is not uncommon to encounter post-surgical complications after horizontal guided bone regeneration (GBR). The primary aim of this review was to evaluate the incidence and types of complications that occur after horizontal GBR and propose management strategies to deal with these clinical situations. A secondary aim was to conduct a histomorphometric review of the wound healing process at sites that experienced post-surgical complications after GBR. A keyword search of MEDLINE, EMBASE, and the Cochrane Central Register of Controlled Trials for studies published in English from January 2015 to January 2020 was conducted for the primary aim and 23 studies were selected. A second search addressing the secondary aim was conducted, and five studies were included. Site-level analysis showed that the weighted mean incidence proportion of minor wound dehiscence and minor infections occurring at the augmented site was $9.9 \%[95 \% \mathrm{Cl} 6.4,13.9, P<0.01]$ and $1.5 \%[95 \% \mathrm{Cl} 0.4,3.1, P=0.21)$ respectively. Patient-level analysis showed minor and major complications occurring at a weighted mean incidence proportion of $16.1 \%$ [95\% Cl 11.9, 20.8, $P=0.01]$ and $1.6 \%$ [95\% Cl 0.0, 4.7, $P<0.01]$ respectively, while neurosensory alterations at the donor site was $7.0 \%[95 \% \mathrm{Cl} 1.3,15.5, P<0.01]$. Subgroup analysis also revealed that the use of block grafts increased the incidence proportion of minor post-surgical complications, whereas a staged GBR procedure increased the incidence proportion of both minor and major post-surgical complications. Although exposure of the barrier membrane is often associated with less bone regeneration and graft resorption, the type of membrane used (resorbable or non-resorbable) had no statistically significant influence on any post-surgical complication. Histologically, a layer of fibrous connective tissue instead of bone is commonly observed at the interface between the native bone at the recipient site and the regenerated bone in cases with membrane exposure after GBR procedure. Minor wound dehiscence was the highest incidence proportion of post-surgical complications. Methods ranging from daily application of antiseptics, use of systemic antimicrobials, regular reviews, and total removal of the non-integrated biomaterials are commonly prescribed to manage these post-surgical complications in attempt to minimise the loss of tissue at the surgical site.
\end{abstract}

Keywords: Bone regeneration, Bone transplantation, Wound healing, Complications, Histology

\footnotetext{
* Correspondence: denfjh@nus.edu.sg

'Discipline of Periodontics, National University Centre for Oral Health

Singapore, 9 Lower Kent Ridge Road, Singapore 119085, Singapore

Full list of author information is available at the end of the article
}

\section{Springer Open}

( ) The Author(s). 2020 Open Access This article is licensed under a Creative Commons Attribution 4.0 International License, which permits use, sharing, adaptation, distribution and reproduction in any medium or format, as long as you give appropriate credit to the original author(s) and the source, provide a link to the Creative Commons licence, and indicate if changes were made. The images or other third party material in this article are included in the article's Creative Commons licence, unless indicated otherwise in a credit line to the material. If material is not included in the article's Creative Commons licence and your intended use is not permitted by statutory regulation or exceeds the permitted use, you will need to obtain permission directly from the copyright holder. To view a copy of this licence, visit http://creativecommons.org/licenses/by/4.0/. 


\section{Introduction}

Given the high long-term survival and success rates, dental implants are regarded as the treatment of choice when replacing missing teeth. In order to achieve desirable treatment outcomes, the implants must be placed in prosthetically driven positions to facilitate the fabrication of aesthetically acceptable and functional reconstructions that are maintainable and stable over time. Yet, this ideal situation might not be readily achievable due to the changes in bone volume that occurs within the first 3 months of tooth loss. As such, guided bone regeneration (GBR) has been proposed to restore the lost bone volume to accommodate the dental implant prostheses. In this surgical technique, bone cells are given a protected environment to populate and mature into functional living bone by excluding epithelial cells and connective tissue through the use of barrier membranes and bone grafts $[1,2]$. Although it is highly predictable [3-8] in terms of bone gain, it is a relatively technique sensitive procedure. Therefore, it is not uncommon to experience post-surgical complications after a GBR procedure. Two systematic reviews $[9,10]$ have assessed post-surgical complications in patients who underwent horizontal GBR, but none of these reviews were designed to specifically identify and analyse the different types of complications that occur after the procedure. This review thus seeks to evaluate the incidence and types of complications that occurred after horizontal GBR procedures were performed and propose appropriate management strategies to deal with these clinical situations. Furthermore, there is scarce data on the histomorphometric presentation of a regenerated site with less than ideal healing due to post-surgical complications. As such, the secondary aim for this paper is to review the wound healing process at a site with history of complications arising from a failed GBR procedure.

\section{Materials and methods \\ Search strategy \\ To address the primary aim}

An electronic search of MEDLINE (PubMed), EMBASE, and Cochrane Central Register of Controlled Trials (CENTRAL) databases was performed using the following search terms: ("dental implants"[MeSH Terms] OR "dental implantation, endosseous" [MeSH Terms] OR "implant"”[tw]); ("bone regeneration"[MeSH Terms] OR "bone substitutes"[MeSH Terms] OR "alveolar ridge augmentation"[MeSH Terms] OR "bone transplantation" [MeSH Terms] OR "guided bone regeneration" $[\mathrm{tw}]$ OR "GBR" $[\mathrm{tw}]$ OR "onlay graft" $[\mathrm{tw}]$ ); ("postoperative complications"[MeSH Terms] OR "complication" ${ }^{*}$ "[tw]). Boolean operators (OR, AND) were used to combine the searches. Hand searching of the included journals was also conducted to ensure completeness of the search.
Studies that were included were as follows: (a) observational (case-control, prospective cohort studies, and case series) or interventional (randomised controlled clinical trials) studies published in the English language from January 2015 to January 2020, (b) horizontal ridge defects were present, (c) horizontal GBR (defined as the use of a space-maintaining bone graft with a barrier membrane) was carried out in healed ridges, (d) postsurgical complications were reported as a primary or secondary outcome, and (e) studies had to recruit more than 15 human subjects for horizontal GBR and were planned for implant placement.

Studies were excluded if (a) other forms of bone augmentation, besides horizontal GBR, were performed at the same surgical site (e.g. vertical GBR, sinus augmentation, ridge split); (b) around fresh extraction sites or immediate implants or implants with bone dehiscence due to peri-implantitis; (c) had concurrent periodontal plastic surgeries (e.g. free gingival grafts, frenectomies) performed; and (d) patients with conditions or are on medications that interfere with bone metabolism (e.g. osteoporosis), a history of head and neck radiotherapy or have severe metabolic disorders (e.g. uncontrolled diabetes mellitus).

The review for the primary aim was prepared according to the Preferred Reporting Items for Systematic Review and Meta-Analyses (PRISMA) checklist [11].

\section{To address the secondary aim}

An electronic search of the PubMed database of the US National Library of Medicine was conducted using the following search terms: "wound dehiscence" OR "dehiscence" OR "flap dehiscence" OR "membrane exposure" OR "graft exposure" OR "graft failure" OR "infection") AND ("ridge augmentation" OR "GBR" OR "guided bone regeneration") AND ("wound healing" or "healing"). Hand searching of the included journals was also conducted to ensure completeness of the search. Studies that were selected (a) were published in English from January 1965 to January 2020; (b) performed GBR procedures; and (c) reported on histological and/or morphometric outcomes of sites in humans or animals where compromised healing such as infection, graft exposure, and/or wound dehiscence had occurred. Studies associated with alveolar ridge preservation or periodontal regeneration of alveolar bone defects around teeth were excluded.

\section{Data extraction and management}

Data was extracted by two reviewers (JT and JL) who independently screened the titles, abstracts, and full texts of the included studies. Full-text examination was done for studies with insufficient information from the titles or abstracts to make a definitive decision, and any 
disagreement between the reviewers was resolved through discussion. To address the primary aim, the data from the studies eligible for selection was then extracted into standardised forms which included: the study design, number of subjects, number of surgical sites, mean age, smoking status, periodontal status, bone graft and barrier membrane used, number of implants placed, staged/simultaneous surgery, implant survival and success rate, follow-up period, horizontal bone gained after surgery, graft resorption rate, and number and rate of complications at the augmented and donor sites subclassified into its different types of complications. To address the secondary aim, information extracted from each study included the study model, defect type, healing period, device used, clinical presentation, and histological presentation of the wound.

\section{Risk of bias assessment}

Two assessment tools were used to assess the risk of bias for the primary aim of the review. For observational studies and interventional studies, quality assessment was done using the Risk of Bias in Non-randomized studies-of Interventions (ROBINS-I) tool and Cochrane risk-of-bias tool 2.0 (ROB 2) respectively, as recommended by the Cochrane Handbook for Systematic Reviews of Interventions 6.0 [12, 13]. Risk of bias for observational studies was assessed for bias (1) due to confounding, (2) in selection of participants, (3) in classification of interventions, (4) due to deviations for intended interventions, (5) due to missing data, (6) in measurements of outcomes, and (7) in selection of the reported result. Bias was categorised as low, moderate, serious, or critical. Risk of bias for interventional studies were assessed for bias (1) arising from randomisation, (2) deviations from intended interventions, (3) missing outcome data, (4) measurement of outcome, and (5) selection of reported result. Bias was categorised as low, high, or some concerns. Assessment of risk of bias was done independently by two reviewers (JT and JL) and any disagreement was resolved through discussion.

\section{Data synthesis}

Meta-analyses were conducted to estimate the overall incidence proportion with $95 \%$ confidence interval according to the different types of post-surgical complications, which include site-level analysis of minor wound dehiscences and minor infections at the augmented site, and patient-level analysis of the total minor and major complications occurring at the augmented site, and neurosensory alterations at the donor site. The incidence proportion was transformed using the Freeman-Tukey double arcsine transformation to stabilise the variance [14]. The random effects model was used in the meta-analyses to account for heterogeneity among studies. The statistical heterogeneity between studies was assessed using Cochran's $Q$ test and the $I^{2}$ statistic. The $I^{2}$ values of $25 \%, 50 \%$, and $75 \%$ were considered to be of low, moderate, and high levels of heterogeneity respectively
The publication bias was evaluated with the funnel plot and the Begg-Mazumdar's rank test [15]. To assess potential confounding factors, subgroup meta-analyses were performed to investigate the effect of the following variables: type of study, type of bone graft used (particulate or block), type of membrane used (resorbable or non-resorbable), and type of GBR technique (staged or simultaneous) on the different types of complications reported. The differences between subgroups were compared using the chi-squared test. All analyses were conducted using statistical software ( $\mathrm{R}$, version 3.63). A $P$ value $<0.05$ was considered statistically significant.

\section{Results}

A flow diagram depicting the selection process is shown in Fig. 1a. The database and hand search yielded a total of 2765 publications, of which 44 publications were selected for full-text examination, and 21 publications were excluded (Additional file 1). A final list of 23 publications fulfilled the selection criteria for the primary aim of this review. Meanwhile for the secondary aim, the database and hand searches yielded a total of 233 and two publications respectively. Thereafter, 11 publications were selected for full-text examination, but only five publications were eligible for final review (Fig. 1b).

\section{Study design and characteristics}

Out of the 23 studies (Table 1), there were 11 randomised controlled clinical trials [21-24, 26, 29-32, 36, 37, 39], one prospective cohort study $[34,40]$, three retrospective cohort studies $[18,20,33]$, and eight case series $[16,17$, $19,25,27,28,35,38,41-43]$, of which two research groups independently published two follow-up papers on the same study cohort [21, 22, 27, 28], and they have been collectively grouped under one study name for this analysis. The follow-up period after ridge augmentation or implant placement was reported in all studies except two [16, 35], and it ranged from 3.1 months to 10 years. Two studies excluded smokers [30, 38], 14 studies reported periodontal status of subjects $[16-18,21-23,25-30,35$, $36,40-43]$, and excluded subjects with untreated periodontal disease, or with a full mouth plaque score and full mouth bleeding score of more than $25 \%$.

\section{Surgical procedure and biomaterials used}

A total of 11 studies used the staged GBR approach only [16, 18-20, 27-29, 31-34], two studies included both staged and simultaneous GBR [17, 35], and the remaining ten studies performed GBR with simultaneous implant placement [21-26, 30, 36-38]. Onlay grafts were used in eight studies, of which six studies obtained grafts from intra-oral donor sites (ramus/symphysis/zygoma) [16, 18-20, 29, 34], one used extra-oral donor sites (iliac crest) [31], while the remaining study used a xenograft 
a.

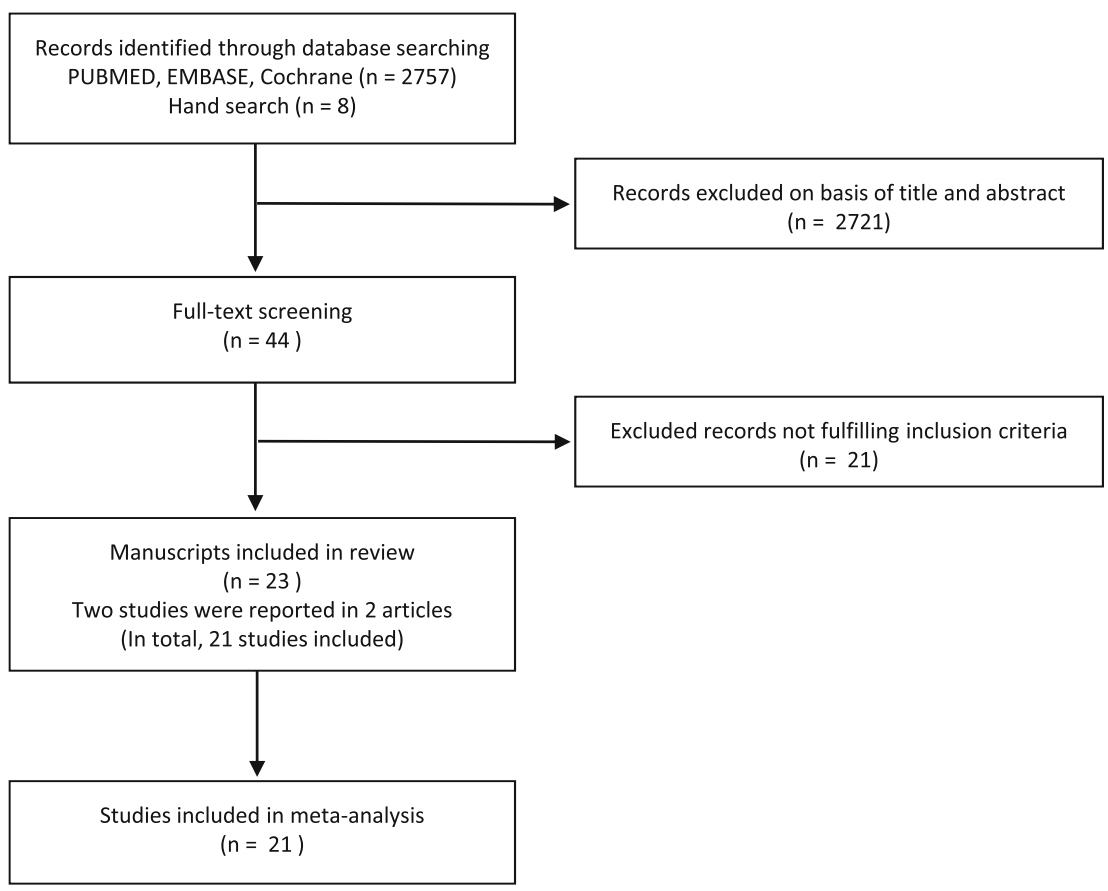

b.

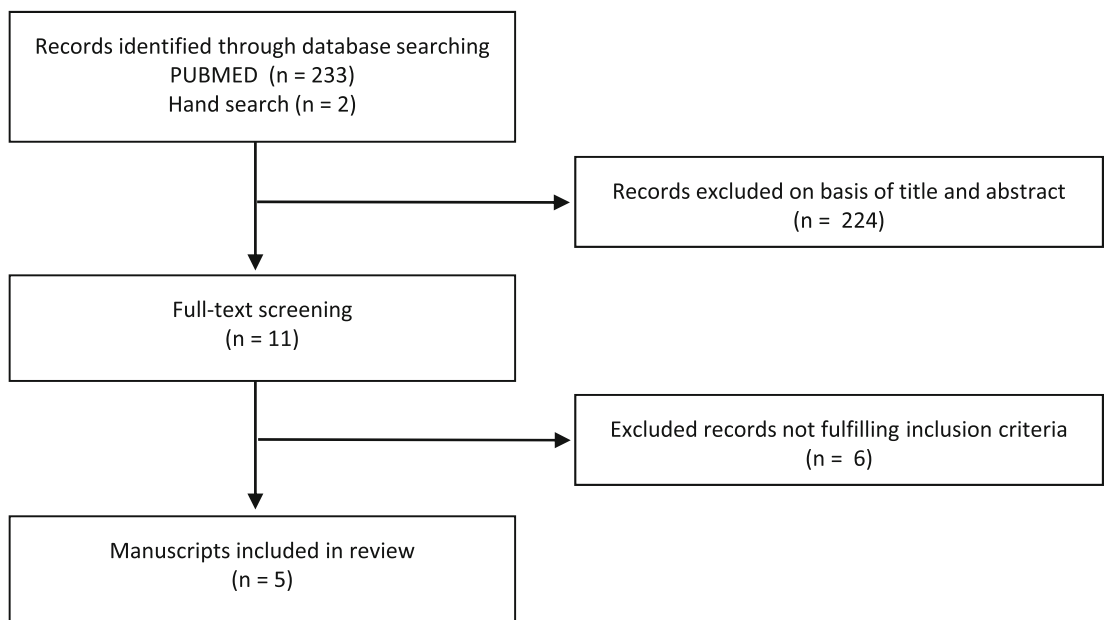

Fig. 1 a Flow diagram of publications showing the study selection process for the primary aim of the study. $\mathbf{b}$ Flow diagram of publications showing the study selection process for the secondary aim of the study

(deproteinised bovine bone mineral (DBBM)) block [26]. The most commonly used particulate bone substitute material in the included studies was DBBM. A majority of the studies also used resorbable collagen barrier membranes $[16-30,32,34-38]$, three used a nonresorbable expanded polytetrafluoroethylene (ePTFE) membrane $[21,22,33]$, one used a resorbable polylactic (PLA) membrane [24], and one used a plasma rich in growth factors (PRGF) membrane [31].

\section{Post-surgical complications}

Minor wound dehiscence was defined as sites where the surgical incision reopened, resulting in a slight gaping wound or where the barrier membrane was exposed but resolved with wound care. The site-level weighted mean incidence proportion of such minor wound dehiscence occurring at augmented sites was $9.9 \%[95 \% \mathrm{CI}=6.4$, 13.9, $P<0.01$ ] (Fig. 2a). Minor infections consisted of sites with localised suppuration or swelling that resolved 


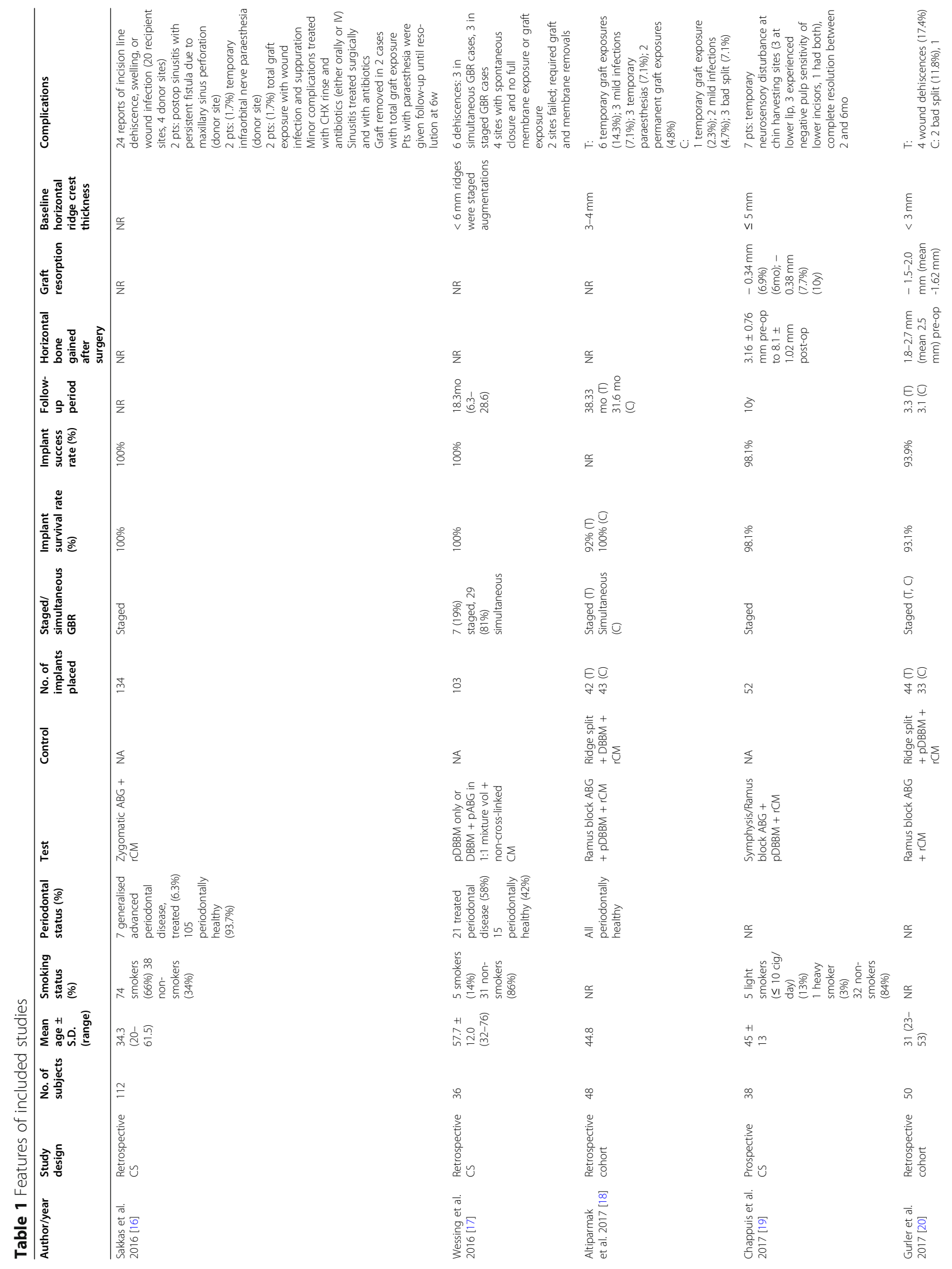




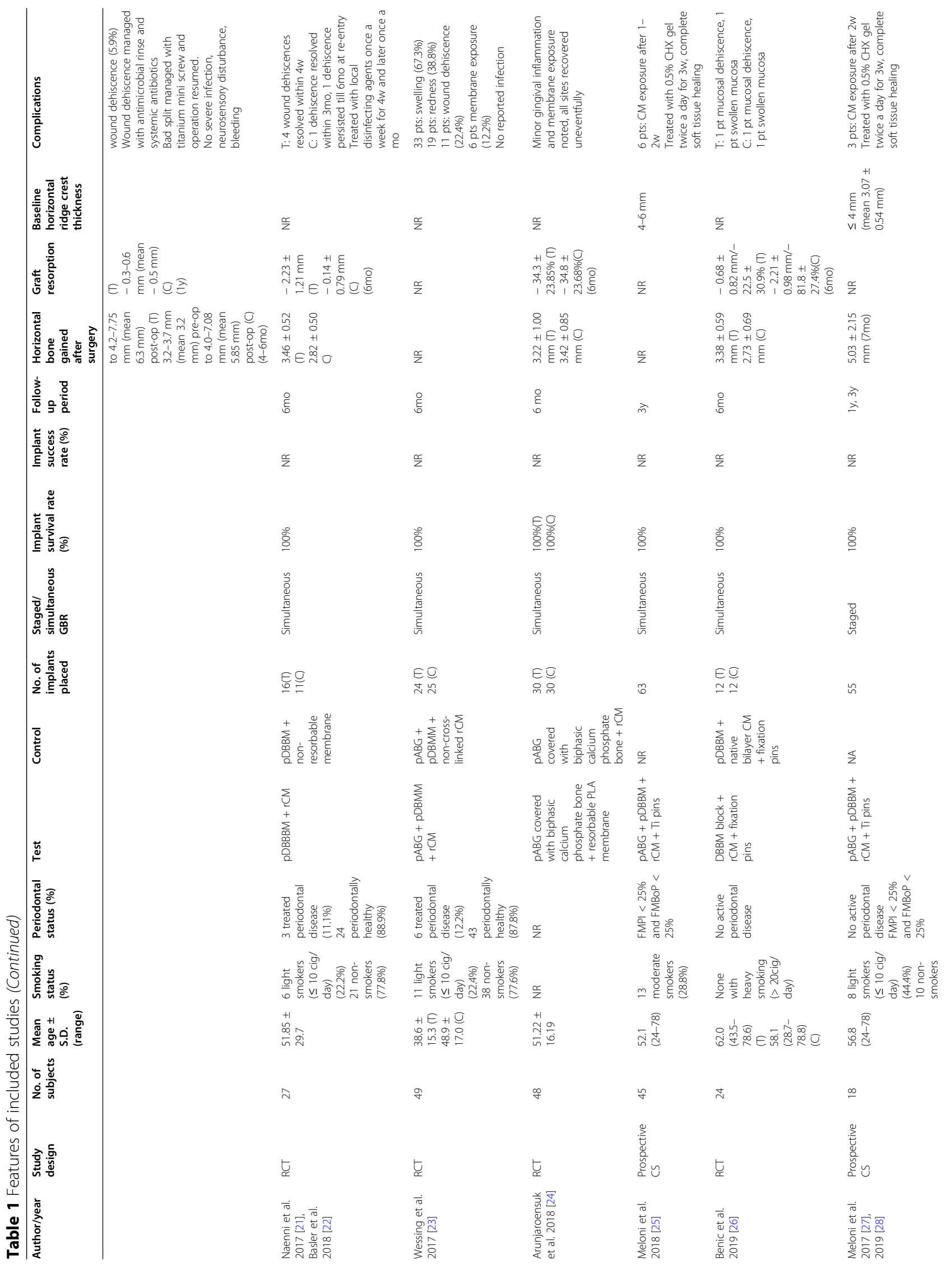




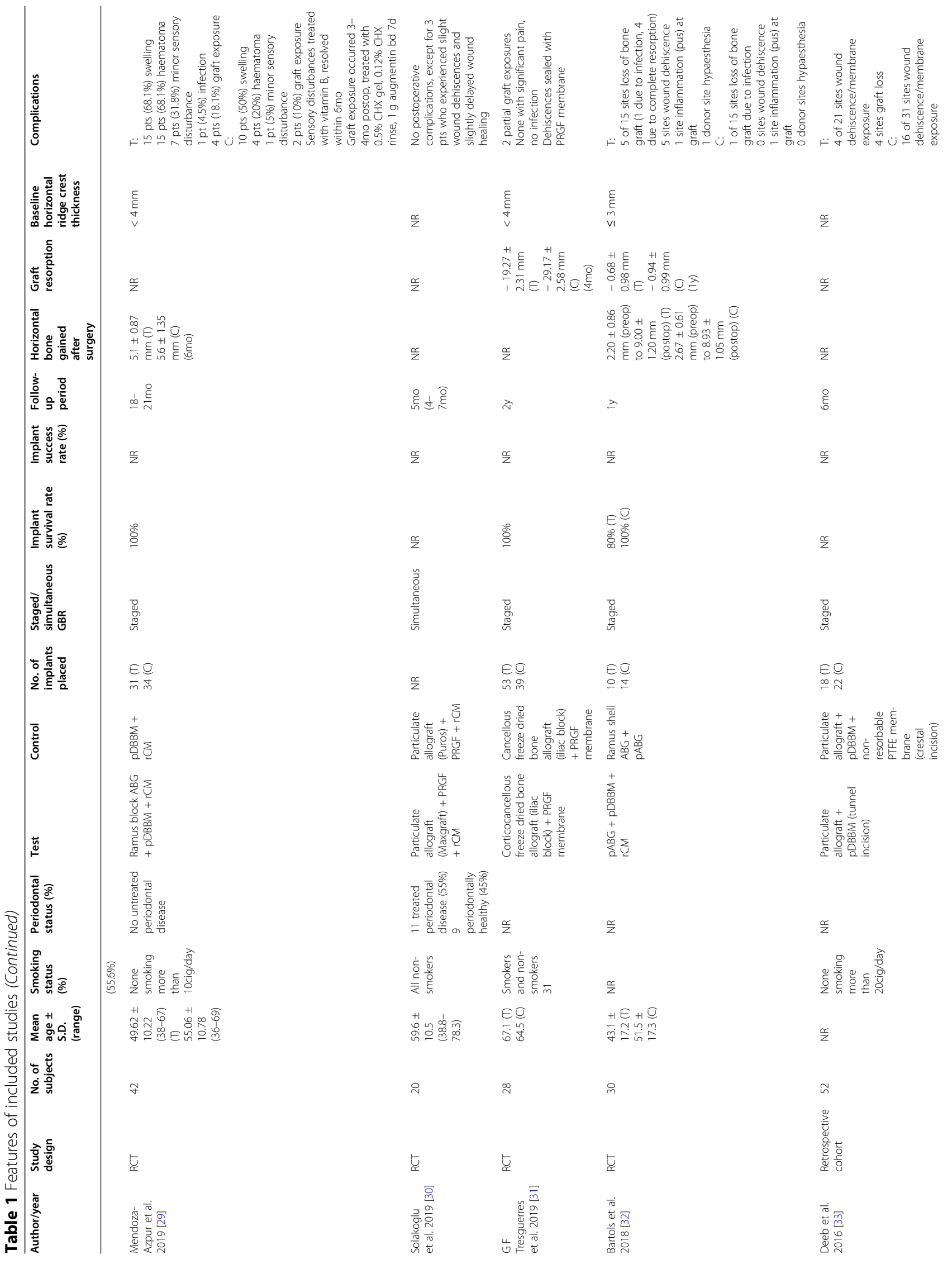




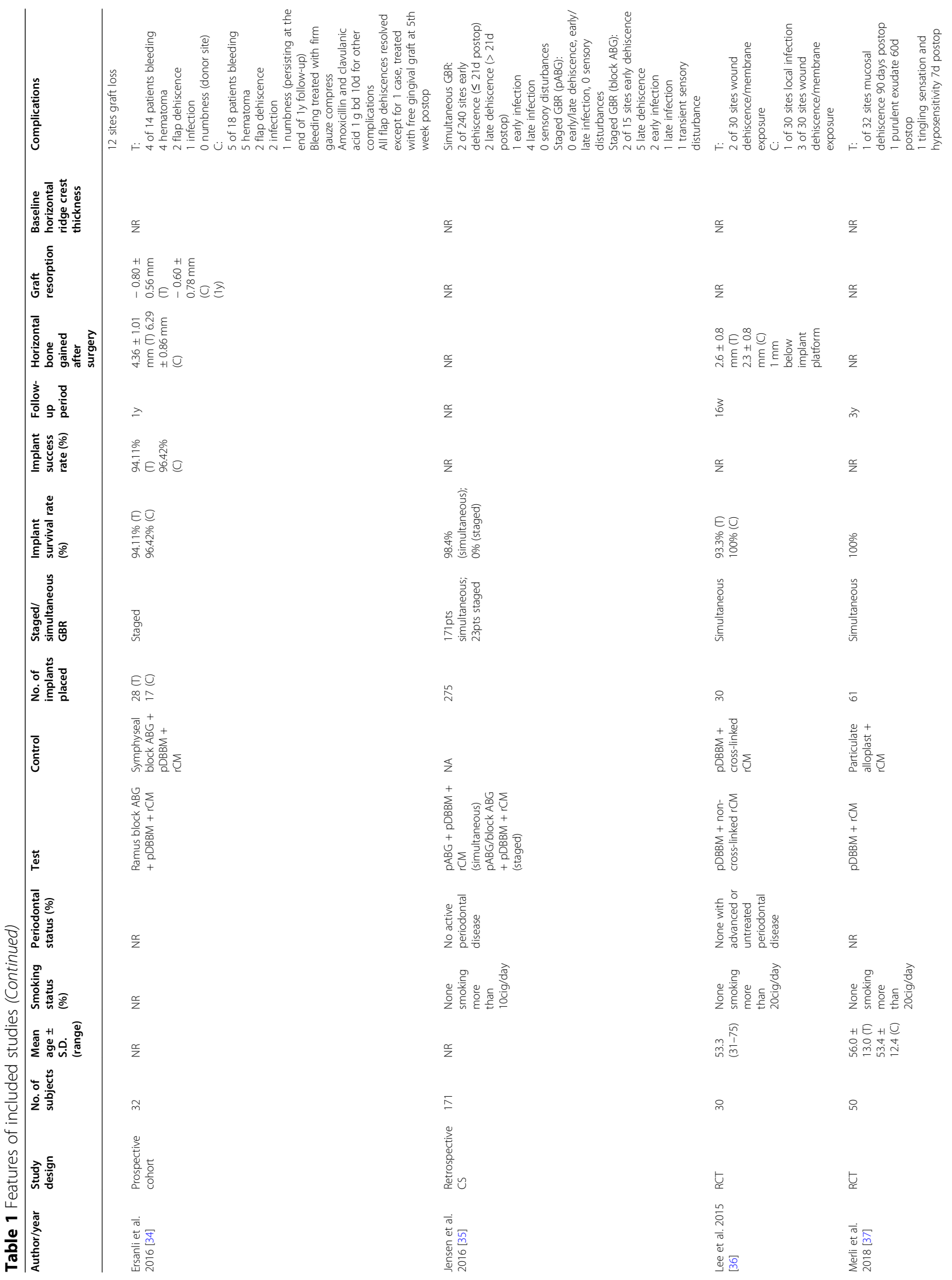




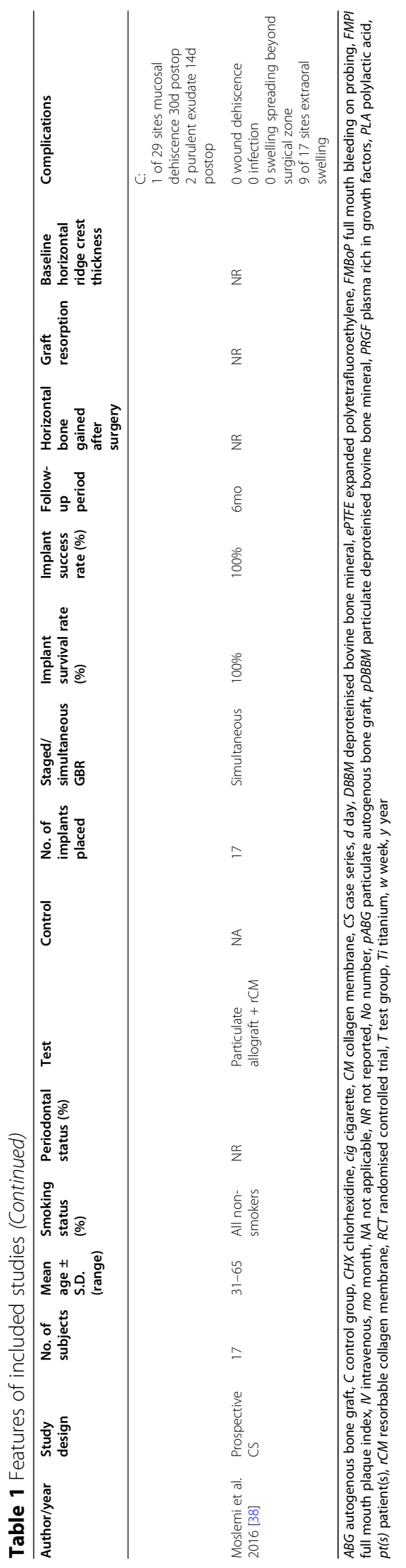




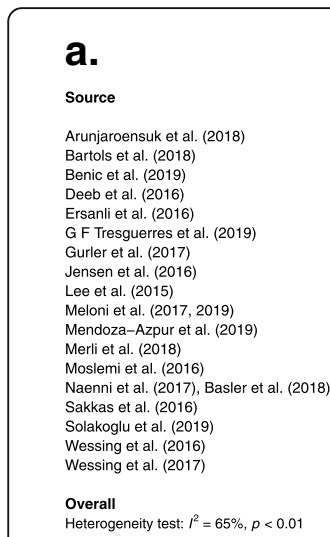

b.
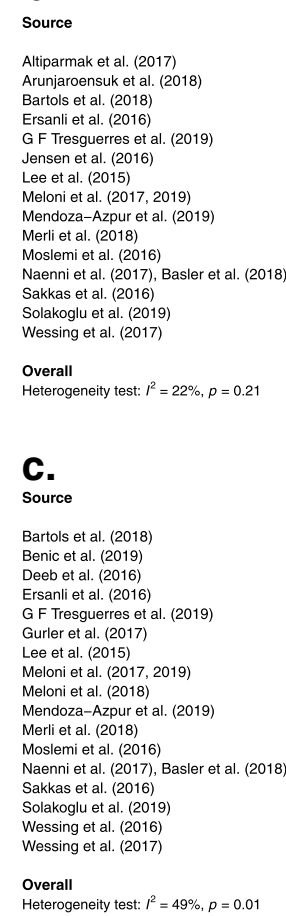

\section{d. \\ Source}

Altiparmak et al. (2017) Arunjaroensuk et al. (2018) Bartols et al. (2018) Benic et al. (2019)
Deeb et al. (2016) Ersanli et al. (2016) G F Tresguerres et al. (2019) Gurler et al. (2017) Lee et al. (2015)
Meloni et al. (2017, 2019) Meloni et al. (2018) Merli et al. (2018)
Moslemi et al. (2016) Naenni et al. (2017), Basler et al. (2018) Sakkas et al. (2016) Solakoglu et al. (2019) Wessing et al. (2016)
Wessing et al. (2017)

Overall

Heterogeneity test: $I^{2}=71 \%, p<0.01$
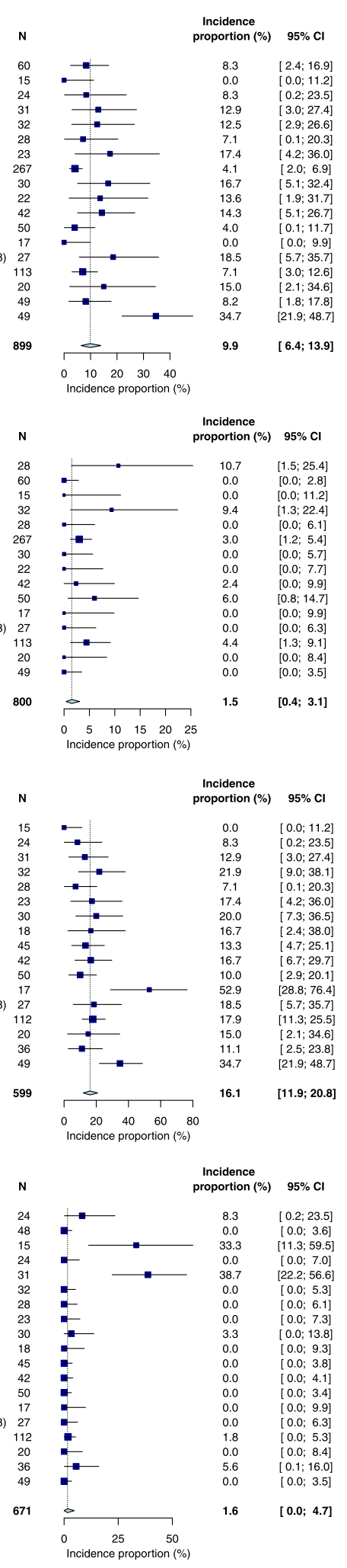

Fig. 2 a Forest plot presenting weighted mean incidence proportion of minor wound dehiscences per augmented site. $\mathbf{b}$ Forest plot presenting weighted mean incidence proportion of minor infections per augmented site. c Forest plot presenting weighted mean incidence proportion of total minor complications at the augmented site per patient. $\mathbf{d}$ Forest plot presenting weighted mean incidence proportion of total major complications at the augmented site per patient. e Forest plot presenting weighted mean incidence proportion of neurosensory alterations at donor site per patient

with antiseptics and/or antibiotics, and this occurred at a weighted mean incidence proportion of $1.5 \%$ [95\% CI $=0.4,3.1, P=0.21$ ] at a site-level (Fig. 2b). Both wound dehiscence and minor infections could be cumulatively classified as minor complications and the overall patient-level weight mean incidence proportion was 16.1\% [95\% CI = 11.9, 20.8, $P=0.01]$ (Fig. 2c).

Major complications referred to persistent or worsening infections, or graft failure which resulted in the need for its partial or total removal the site of bone augmentation. The overall weighted mean incidence proportion of these major complications was $1.6 \%[95 \% \mathrm{CI}=0.0$, 4.7, $P<0.01$ ] at a patient level (Fig. 2d). Neurosensory alterations at the donor site were also reported in studies utilising autologous grafts and included symptoms such as lip paraesthesia and negative pulp sensitivity to the lower incisors. Such alterations had a weighted mean incidence proportion of $7.0 \%[95 \% \mathrm{CI}=1.3,15.5, P<0.01]$ at a patient-level (Fig. 2e) and could reportedly last for more than 6 months [34]. Funnel plots reported no publication bias except on reporting major complications (Additional file 2).

Subgroup analysis was done based on the type of study, type of bone graft used (particulate or block), type of membrane used (resorbable or non-resorbable), and type of GBR technique (staged or simultaneous) (Additional file 3). Site-level analysis showed that the use of block grafts resulted in a significantly higher incidence proportion of minor infections at augmented sites $(5.7 \%$ [95\% CI 1.8, 11.1, $P=0.12]$ ) compared to particulate grafts $(0.4 \%$ [95\% CI 0.0, 1.5, $P=0.80])$. On the other hand, the type of membrane used did not seem to have any effect on the incidence proportion of any postsurgical complication. A staged GBR procedure also resulted in a statistically significant higher site-level incidence of minor infections $(4.2 \%$ [95\% CI 1.6, 7.5, $P=$ $0.22])$ compared to simultaneous GBR $(0.6 \%$ [95\% CI $0.0,1.8, P=0.52])$. This was also mirrored at the patient-level analysis where the incidence proportion of major complications for staged GBR stood at 5.2\% [95\% CI 0.1, 17.6, $P<0.01])$,compared to simultaneous GBR (0.0\% [95\% CI 0.0, 0.8, $P=0.98]$ ). 


\section{Management of post-surgical complications}

The management of post-surgical complications was only reported in thirteen studies $[16,17,19-22,24,25$, $27-29,31,34]$. When a minor wound dehiscence occurred, the included studies reported common management regimes that consisted of either the use of antiseptics, systemic antibiotics, or site repair with autogenous tissue or growth factors (Table 1). Three studies advised patients to institute home care management by applying $0.5 \%$ chlorhexidine gel twice a day for 3 weeks at the dehisced site $[25,27,28]$. Two studies nursed wound dehiscence sites by recalling patients once a week for 4 weeks for professional local disinfectant application, and once a month thereafter until complete resolution [21, 22]. Two studies reported management of wound dehiscences with exposed graft materials by removing the sequestered bone [16] and treating the site with a combination of an antimicrobial mouth rinse and systemic antibiotics $[16,20]$. Two studies reported uneventful and spontaneous healing of dehisced sites [17, 24]. The need for additional surgical intervention to manage minor wound dehiscences has also been looked at. While one study treated all minor wound dehiscences immediately with a PRGF membrane [31], another study treated all wound dehiscences with an initial course of systemic amoxicillin and clavulanic acid for 10 days and only proceeded to graft a dehisced site with a free gingival graft at the fifth week after surgery due to nonresolution [34]. One study reported late complications emerging only 3 to 4 months after the initial GBR, and they were treated with $0.5 \%$ chlorhexidine topical gel application, $0.12 \%$ chlorhexidine rinse, and a 1 week course of amoxicillin and clavulanic acid [29]. Minor infections such as suppuration were treated either only with systemic antibiotics [34] or with the addition of a chlorhexidine mouth rinse [16]. Regardless of which treatment strategy being employed, all these management regimes resulted in complete soft tissue healing, except in one study cohort where one case of minor dehiscence persisted until re-entry surgery 6 months later $[21,22]$, and in two studies where there were isolated instances of total graft exposure which necessitated complete removal of the graft and membrane $[16,17]$. When graft failure occurred, the two reported cases in one study declined further bone augmentation procedures [16], and the one case in the second study experienced another surgical failure after a repeated augmentation procedure, with success reported only after the third time when autogenous bone was used instead of a combination of autogenous and demineralised bovine bone mineral [17]. For patients who reported having neurosensory alterations at the donor sites, they were given regular follow-up review appointments [16, 19, 29], with one study prescribing patients with a course with vitamin B [29]. These studies reported complete neurosensory resolution between 2 and 6 months.

\section{Heterogeneity test}

There was low heterogeneity among studies reporting the incidence proportion of minor infections at a sitelevel $\left(I^{2}=22 \%, P=0.21\right)$. There was moderate heterogeneity $\left(I^{2}=49 \%, P=0.01\right)$ among studies reporting on the total minor complications at a patient-level, moderately high heterogeneity $\left(I^{2}=65 \%, P<0.01\right)$ among studies reporting on minor wound dehiscence at a site level, and high heterogeneity $\left(I^{2}=71 \%, P<0.01 ; I^{2}=\right.$ $75 \%, P<0.01)$ among studies reporting on the total major complications and neurosensory alterations at a patient-level respectively.

\section{Risk of bias assessment}

Ten randomised controlled clinical trials were assessed using the ROB 2 (Fig. 3a). Two observational studies $[32,37]$ had an overall low risk of bias, and eight observational studies [21-24, 26, 29-31, 36] had some concerns in bias. Four observational studies were assessed using the ROBINS-I tool (Fig. 3b). Three studies [20, 33, 34] had an overall moderate risk of bias, while one study had a serious risk of bias [18].

\section{Histomorphometric analysis in sites with post-surgical complications}

Out of the five studies reviewed, three studies involved human subjects [44-46], while two were animal studies $[47,48]$ (Table 2). For these studies, histological assessment was conducted at sites experiencing wound dehiscence and graft exposures post-GBR. Graft failure and its subsequent membrane and graft loss was observed in one study. The majority of the studies involved the use of a particulate bone graft [44-47], except for one which used an autogenous onlay graft [48]. The membranes of choice were either a resorbable collagen membrane or an ePTFE membrane. None of the studies included morphometric analysis of sites with post-GBR complications.

Of the three human studies, biopsies for histological analysis were obtained during second-stage surgeries, which took place between 6 and 7 months after the initial surgeries. When a resorbable collagen membrane was used [44-46], most sites with clinical evidence and history of wound dehiscences had complete wound closure within 6 weeks from the initial surgery. In spite of the exposure, none of the sites presented with evidence of inflammation, degradation, swelling, erythema, or suppuration throughout the period of study. Conversely, when a non-resorbable ePTFE membrane was used [45], some dehiscences failed to heal even after the initial 


\begin{tabular}{|c|c|c|c|c|c|c|}
\hline \multicolumn{7}{|l|}{ a. } \\
\hline & Pre- & At intervention & & Post-intervention & & Overall risk of \\
\hline Author (Year) & Randomisation & $\begin{array}{c}\text { Effect of } \\
\text { assignment to } \\
\text { intervention }\end{array}$ & $\begin{array}{l}\text { Missing } \\
\text { outcome data }\end{array}$ & $\begin{array}{l}\text { Measurement } \\
\text { of outcome }\end{array}$ & $\begin{array}{l}\text { Selection of } \\
\text { reported result }\end{array}$ & $\begin{array}{c}\text { Low/ Some } \\
\text { concerns/ High }\end{array}$ \\
\hline $\begin{array}{l}\text { Arunjaroensuk et al. } \\
\qquad(2018)^{19}\end{array}$ & Some concerns & Low & Low & Low & Some concerns & Some concerns \\
\hline Bartols et al. (2018) ${ }^{24}$ & Low & Low & Low & Low & Low & Low \\
\hline Benic et al. $(2019)^{20}$ & Low & Low & Low & Low & Some concerns & Some concerns \\
\hline $\begin{array}{l}\text { G F Tresguerres et al. } \\
(2019)^{23}\end{array}$ & Low & Low & Low & Low & Some concerns & Some concerns \\
\hline Lee et al. $(2015)^{25}$ & Low & Some concerns & Low & Low & Some concerns & Some concerns \\
\hline $\begin{array}{c}\text { Mendoza-Azpur et al. } \\
(2019)^{21}\end{array}$ & Low & Some concerns & Low & Low & Low & Some concerns \\
\hline Merli et al. $(2018)^{26}$ & Low & Low & Low & Low & Low & Low \\
\hline $\begin{array}{l}\text { Naenni et al. }(2017)^{16} \\
\text { Basler et al. }(2018)^{17}\end{array}$ & Low & Low & Low & Low & Some concerns & Some concerns \\
\hline $\begin{array}{l}\text { Solakoglu et al. } \\
\qquad(2019)^{22}\end{array}$ & Low & Low & Low & Low & Some concerns & Some concerns \\
\hline $\begin{array}{l}\text { Wessing et al. } \\
(2017)^{34}\end{array}$ & Low & Some concerns & Low & Low & Low & Some concerns \\
\hline
\end{tabular}

b.

\begin{tabular}{|c|c|c|c|c|c|c|c|c|}
\hline \multirow{2}{*}{$\begin{array}{l}\text { Author } \\
\text { (Year) }\end{array}$} & \multicolumn{2}{|c|}{ Pre-intervention } & \multicolumn{2}{|c|}{ At intervention } & \multicolumn{3}{|c|}{ Post-intervention } & \multirow{2}{*}{$\begin{array}{c}\begin{array}{c}\text { Overall } \\
\text { risk of bias }\end{array} \\
\text { Low/ } \\
\text { moderate/ } \\
\text { serious/ } \\
\text { critical }\end{array}$} \\
\hline & $\begin{array}{l}\text { Bias due to } \\
\text { confounding }\end{array}$ & $\begin{array}{l}\text { Bias in } \\
\text { selection of } \\
\text { participants }\end{array}$ & $\begin{array}{l}\text { Bias in } \\
\text { classification of } \\
\text { interventions }\end{array}$ & $\begin{array}{l}\text { Bias due to } \\
\text { deviations } \\
\text { from intended } \\
\text { interventions }\end{array}$ & $\begin{array}{c}\text { Bias due } \\
\text { to missing } \\
\text { data }\end{array}$ & $\begin{array}{c}\text { Bias in } \\
\text { measurement } \\
\text { of outcomes }\end{array}$ & $\begin{array}{l}\text { Bias in } \\
\text { selection of } \\
\text { reported } \\
\text { result }\end{array}$ & \\
\hline $\begin{array}{c}\text { Altiparmak } \\
\text { et al. } \\
(2017)^{30}\end{array}$ & Serious & Moderate & Moderate & Moderate & Low & Moderate & Moderate & Serious \\
\hline $\begin{array}{c}\text { Deeb et al. } \\
(2016)^{32}\end{array}$ & Moderate & Low & Moderate & Low & Low & Moderate & Moderate & Moderate \\
\hline $\begin{array}{c}\text { Ersanli et al. } \\
(2016)^{28}\end{array}$ & Moderate & Low & Moderate & Low & Low & Moderate & Moderate & Moderate \\
\hline $\begin{array}{c}\text { Gurler et al. } \\
(2017)^{31}\end{array}$ & Low & Low & Low & Low & Moderate & Low & Moderate & Moderate \\
\hline
\end{tabular}

Fig. 3 a Risk of bias of included randomised controlled clinical trials. b Risk of bias of included observational studies

healing period and certain sites required premature removal of the membrane and bone graft.

Two studies showed no difference in terms of bone quality between the membranes with or without membrane exposure at 6 to 7 months [44, 45]. In addition, tissue apposition and ingrowth into the gaps between the collagen layers had occurred independent of membrane exposure. Though there was a possibility of bacterial contamination of the membrane during the period of wound dehiscence, no granulocytic infiltration was noted at 7 months. However, there was one study that observed that sites with membrane exposure had lower remodelling rates, with some sites displaying missing or minimal osteogenesis [46]. Sites with a lack of osteogenesis showed the graft material being covered by dense collagen tissue populated with multinucleated cells.

Two animal studies were included in this review. In the first study, wound dehiscence and inflammation occurred in two out of six sites within the first week postsurgery, and complete wound closure was achieved by the end of 6 weeks. Histological analysis at eighth week revealed that sites with history of wound dehiscence 
Table 2 Features of included studies

\begin{tabular}{|c|c|c|c|c|c|}
\hline $\begin{array}{l}\text { Author/ } \\
\text { year }\end{array}$ & $\begin{array}{l}\text { Study } \\
\text { model }\end{array}$ & Defect & $\begin{array}{l}\text { Healing } \\
\text { period }\end{array}$ & Device & $\begin{array}{l}\text { Clinical/gross presentation of } \\
\text { dehiscence }\end{array}$ \\
\hline $\begin{array}{l}\text { Friedmann } \\
\text { et al. } 2001 \\
\text { [44] }\end{array}$ & $\begin{array}{l}16 \\
\text { human } \\
\text { subjects }\end{array}$ & Chronic & $7 \mathrm{mo}$ & $\begin{array}{l}\text { pDBBM covered with } \\
\text { bovine type I collagen } \\
\text { cross-linked CM }\end{array}$ & $\begin{array}{l}\text { Within first 14d: } \\
\text { Exposure of CM } \\
7 \text { out of } 10 \text { dehiscences } \\
\text { completely closed within } \\
\text { following } 14 \text { days } \\
1 \text { site completely covered by new } \\
\text { gingiva with some exfoliated } \\
\text { pDBBM after } 4 \mathrm{w} \\
2 \text { sites completely closed only } \\
14 \mathrm{~d} \text { after the } 6 \mathrm{w} \text { review } \\
\text { None of the dehisced sites } \\
\text { showed any signs of } \\
\text { inflammation, degradation, } \\
\text { swelling, redness, exudation at } \\
\text { any time point }\end{array}$ \\
\hline
\end{tabular}

[45] subjects

$\begin{array}{llll}\text { Friedmann } & 14 & \text { Chronic } & 7 m o \\ \text { et al. } 2002 & \text { human } & & \\ \text { [45] } & \text { subjects } & & \end{array}$

pDBBM covered either with bovine type I collagen cross-linked CM or ePTFE membrane
With bovine type I CM:

Within first $14 \mathrm{~d}$ :

9 out of 14 sites had exposure of

$\mathrm{CM}$, complete closure after another $4 \mathrm{w}$

None of the dehisced sites showed any signs of inflammation, degradation, swelling, redness, exudation at any time point

Uneventful delayed pattern of gingival healing

With ePTFE membrane:

Exposure during and after initial

healing period

Some required premature retrieval of membrane due to non-healing

One site required complete removal of graft and membrane due to infection and severe inflammation

$\begin{array}{llll}\text { Friedmann } & 12 & \text { Chronic } & 6 \mathrm{mo} \\ \text { et al. } 2015 & \text { human } & & \\ \text { [46] } & \text { subjects } & & \end{array}$

Biphasic calcium
7 out of 13 sites had compromised healing (wound dehiscence and/or graft exposure)
Histological presentation of dehiscence

At 7mo:

No difference in appearance between membranes with and without exposure Possible that bacteria adhered to exposed membrane surfaces, but no granulocytic infiltration observed at $7 \mathrm{mo}$ Tissue apposition and ingrowth into gaps between the collagen layers occurred independent of membrane exposure

At 7mo:

Dehiscence occurrence had no resulting difference in bone quality phosphate covered either with non-crosslinked CM or crosslinked CM

At 6mo:

Low remodelling rates

Osteogenesis detected in 4 out of the 7 sites, with the remaining displaying missing or minimal osteogenesis In cases with absent osteogenesis, the graft material was covered predominantly by dense collagen tissue populated by multinuclear cells resembling either osteoclasts or epitheloid giant cells with intermingled mononuclear cells

At 8w:

Less bone regeneration, remnants of cross-linked collagen barrier with signs of inflammation

Dome shape contour of newly formed bone not apparent

At 15d:

With ePTFE membrane:
15, 30, $A B G$ covered with either
60,120 , resorbable membrane 180d or ePTFE

$\mathrm{CM}$ and signs of local

porcine type I and II CM inflammation

or

At 6w:

Wound closure complete, no inflammation observed

$\begin{array}{lll}\text { Donos } & 30 & \text { None } \\ \text { et al. 2002 } & \text { Wistar } & \text { (graft } \\ \text { [48] } & \text { rats } & \begin{array}{l}\text { placed } \\ \text { directly }\end{array} \\ & & \begin{array}{l}\text { did } \\ \end{array}\end{array}$

With ePTFE membrane: sites

With resorbable membrane:

Membrane exposure in 4 out of 6 sites

At 30d:

With ePTFE membrane:
Gratt contained osteocytes and had maintained its height. Periphery of graft had scalloped appearance due to

resorption lacunae. Zone of connective tissue with numerous leucocytes, lymphocytes, plasma cells between graft and membrane. Richly vascularised 
Table 2 Features of included studies (Continued)

Author/ Study Defect Healing Device year period

\section{Clinical/gross presentation of Histological presentation of dehiscence \\ dehiscence}

Membrane lost in 1 site, membrane exposure in remaining 4 out of 5 sites With resorbable membrane: Membrane exposure in 3 out of 6 sites

At 60d:

With ePTFE membrane: Microimplant lost in 5 out of 6 sites making histological preparation impossible. Membrane exposure in remaining site

With resorbable membrane: Membrane exposure in 4 out of 6 sites

At 120d:

With ePTFE membrane:

Microimplant, graft, membrane lost in 3 sites. Only membrane was lost in remaining 3 sites With resorbable membrane: Microimplant and graft lost in 2 sites. Membrane exposure in 3 out of the remaining 4 sites At 180d:

With ePTFE membrane:

Microimplant, graft, membrane lost in 5 sites. Only membrane was lost in remaining site With resorbable membrane: Microimplant, graft, membrane lost in 2 sites recipient site

With resorbable membrane: connective tissue

At 30d:

With ePTFE membrane: With resorbable membrane: granulation tissue between graft and Exposed parts of membrane were fragmented and surrounded by connective tissue that had inflammatory infiltrate. Non-exposed parts had preserved their structure and embedded in

Graft contained osteocytes, had scalloped surface. Inflammatory infiltrate between membrane and graft. Layer of fibrous connective tissue between the recipient site and graft (as opposed to newly formed immature trabecular bone in continuity between recipient site and graft, at the site with no dehiscence)

Membrane broken into large fragments, encapsulated by fibrous connective tissue with inflammatory cells. Bone graft had significant resorption especially at lateral edges of graft. Remaining parts surrounded by connective tissue with inflammatory infiltrate, and there was no bone continuity between recipient site and graft. Resorption of recipient bone had occurred (as opposed to newly formed mature trabecular bone in continuity between recipient site and graft, at the site with no dehiscence) At 60d:

With ePTFE membrane:

Bone graft had disappeared. Resorption of recipient bone had occurred With resorbable membrane:

Small fragments of membrane could be detected. Bone grafts had empty lacunae. Two sites had graft that maintained its height, while two others the lateral border of the graft was exposed and inflammatory infiltrate was observed adjacent to the graft. Bone continuity between graft and recipient site was not observed in any site with membrane exposure At 120d: With ePTFE membrane: Bone graft partially or almost completely resorbed but two specimens had bone continuity between remaining parts of graft and recipient bone With resorbable membrane:

Small fragments of membrane present adjacent to non-exposed lateral borders of graft. Exposed portion of graft had empty osteocyte lacunae, and height and width of graft was reduced due to resorption. Recipient bone also exhibited resorption. No bone continuity between graft and recipient site (as opposed to bone contact, at sites with no dehiscence)

At 180d:

With ePTFE membrane: 
Table 2 Features of included studies (Continued)

\begin{tabular}{|c|c|c|c|c|c|}
\hline $\begin{array}{l}\text { Author/ } \\
\text { year }\end{array}$ & $\begin{array}{l}\text { Study } \\
\text { model }\end{array}$ & Defect & $\begin{array}{l}\text { Healing Device } \\
\text { period }\end{array}$ & $\begin{array}{l}\text { Clinical/gross presentation of } \\
\text { dehiscence }\end{array}$ & $\begin{array}{l}\text { Histological presentation of } \\
\text { dehiscence }\end{array}$ \\
\hline & & & & & $\begin{array}{l}\text { Only } 1 \text { site had bone graft remaining, } \\
\text { which contained osteocytes and had } \\
\text { maintained its height. Bone continuity } \\
\text { between graft and recipient bone was } \\
\text { observed } \\
\text { With resorbable membrane: } \\
\text { Bone graft completely resorbed in } 1 \text { site. } \\
\text { In remaining } 3 \text { sites, operated area } \\
\text { covered by oral mucosa with very small } \\
\text { remnants of membrane }\end{array}$ \\
\hline
\end{tabular}

$\overline{A B G}$ autogenous bone graft, $C M$ collagen membrane, $d$ day, ePTFE expanded polytetrafluoroethylene, $m$ month, $p A B G$ particulate autogenous bone graft, $p D B B M$ particulate deproteinised bovine bone mineral, $w$ week

during the initial phase of healing displayed less bone regeneration [47]. The other study compared the use of a resorbable membrane against an ePTFE membrane in GBR and analysed the sites histologically at $15,30,60$, 120 , and 180 days. At 15 days, the periphery of the bone graft exhibited a scalloped appearance due to resorption lacunae, and a zone of connective tissue with inflammatory infiltrate and richly vascularised granulation tissue was observed at the interface between the recipient site and the bone graft. At 30 days, sites with membrane exposure had a layer of fibrous connective tissue between the recipient bone and the graft, instead of newly formed trabecular bone in contact with each other as observed at sites that were complication-free. Furthermore, if a resorbable membrane was exposed, it was observed that the membrane had disintegrated into large fragments which were then separately encapsulated by fibrous connective tissue in the presence of inflammatory cells. The associated bone graft materials also had more significant resorption especially at the lateral edges. On top of that, resorption of the recipient native bone site was also observed. The progressive resorption of the remnant bone grafts continued from day 60 to 120 . At 60, 120, and 180 days, none of the membrane exposed sites except one displayed any bone continuity between the graft and recipient native bone [48].

\section{Discussion}

\section{Primary findings}

Minor wound dehiscence, with a weighted mean incidence proportion of 9.9\% [95\% CI 6.4, 13.9, $P<0.01]$ at site-level, is the most common post-surgical complication that occurs after GBR. It can lead to early or late membrane exposure, contamination, infection, and partial or total loss of the graft. Membrane exposure leads to a significant detrimental negative effect on horizontal bone gain, with sites without membrane exposure showing $74 \%$ more bone gain than those with membrane exposure [49]. Despite the relatively high incidence of wound dehiscence, post-surgical infection of the graft is relatively uncommon with a weighted mean incidence proportion of $1.5 \%$ [95\% CI 0.4, 3.1, $P=0.21$ ] for minor infections per augmented site and 1.6\% [95\% CI 0.0, 4.7, $P<0.01]$ for major complications at augmented site per patient. Nonetheless, any complication will potentially lead to increased treatment time and cost to the patient and thus should be avoided or managed in a timely manner should it occur.

The use of cross-linked and non-resorbable membranes has reportedly been associated with a greater incidence of wound dehiscence because of its tendency to revert back to its original shape, instead of staying adapted to the graft site [50,51]. A recent systematic review reported an overall membrane exposure rate of $22.7 \%$ in simultaneous GBR procedures with no significant difference between resorbable and non-resorbable membranes [9]. This is also confirmed by the findings in this systematic review which showed no difference in any post-surgical complication regardless of membrane type.

The use of block grafts and staging a GBR procedure was shown to result in a higher prevalence proportion of post-surgical complications. This may be explained by the fact that sites which require block grafts or staged GBR procedures usually require a larger volume of horizontal augmentation, which can potentially result in greater flap tension, dehiscence, and subsequent post-surgical complications. The use of a block graft, especially those derived only from cortical bone, may reduce the chances of its revascularisation and vitality, which can confer a higher risk of graft necrosis and infection [52].

\section{Secondary findings}

Guided bone regeneration is a predictable surgical procedure when there is proper adaptation and stabilisation of the membrane and maintained flap closure during the healing phase. The animal studies in this review showed that wound dehiscence resulted in less bone regeneration, graft resorption, and a lack of bone continuity between the recipient site and the grafted bone [47, 48]. 
Resorption of the recipient bone can occur as well in such defects. A mild inflammatory reaction, probably a foreign body reaction, was observed 15 days postsurgically. However, when the membrane was exposed to the oral environment, a layer of fibrous connective tissue between the recipient site and the bone graft was almost always observed. The exposure of an ePTFE and a resorbable collagen membrane was constantly associated with a dense chronic inflammatory infiltrate, and the exposed resorbable collagen membrane had almost completely resorbed by 30 days. Persistent unresolved contamination of the membrane eventually led to high rates of graft and membrane loss. The high failure rates depicted in the animal studies are partially due to the inability to institute frequent repeated sessions of general anaesthesia to conduct post-surgical wound management. Perhaps with the frequent reviews and decontamination of the exposed site as mentioned in the earlier section, the incidence of such failures would be much reduced.

One clinical study [46] which investigated the use of non-cross-linked and cross-linked collagen membranes reported lower bone remodelling rates and compromised osteogenesis in sites with dehiscence, which were consistent with the findings from the animal studies. However, the other two clinical trials in this review [44, 45] seemed to suggest that the composition and quality of new bone formation was independent of any episodes of wound dehiscence. This could have been due to the type I collagen cross-linked membranes used in those studies, which might be more resistant to attack by mammalian and bacterial collagenase. Secondly, in spite of the dehiscences, the membranes appeared clinically intact during the healing period, and all the dehisced sites were completely healed after institution of a strict antiseptic regime where patients were instructed to use chlorhexidine gel three times a day at exposed areas and reviewed weekly. None of the dehisced sites in these two studies had any clinical sign of inflammation, swelling, erythema, or suppuration.

\section{Clinical implications}

Many published studies have demonstrated that width of keratinised mucosa, flap thickness, flap tension, vestibular depth, type and size of alveolar defect, and the materials used [53] were related to the occurrence of wound dehiscence. Out of the various factors that could influence success of the GBR procedure, several authors have highlighted the upmost importance of a tension-free flap closure in ensuring complete wound closure and an uneventful healing phase [54-56] and one study in particular emphasised that this factor is more critical than flap thickness in determining surgical success [57]. For most GBR sites, vertical releasing incisions are employed to allow for flap advancement but at sites with large volume of added bone grafts, such incisions alone might still not be adequate to provide for a tension free flap closure. This can be overcome by the addition of periosteal releasing incisions which can allow for an additional flap extension of $5.5 \mathrm{~mm}$ compared to vertical releasing incisions alone [58]. Other authors have also suggested modifying the recipient site flap management by creating longer horizontal extensions at the apical extents of the flap, having secondary flap reflection after membrane fixation, and/or employing a double flap incision design which involves suturing the periosteum before suturing the flap in order to achieve flap passivity [59-61]. During the pre-operative preparative phase, operators should have a clear grasp of the anatomy of the planned surgical site. This knowledge would come in handy especially while designing an access flap for sites planned for large volume augmentation. Operators can then consider and explore the use of more intricate flap designs such as mobilising lingual flap for the mandible or incorporating a sub-orbicularis muscle flap manipulation at the anterior maxilla region to better facilitate in tension free flap closure [56, 62, 63]. However, these advanced surgical techniques are not complication-free and patients might run into risks of developing neurosensory alterations. Though generally uncommon, one should not overlook the possibility of mental and lingual nerve paraesthesia occurring as a result of poor flap preparation and management. A dome-shaped incision around the mental nerve foramen has been suggested to avoid mental nerve damage, while vertical incisions should not be performed on the lingual aspect for fear of lingual nerve damage [61]. Most of these neurosensory alterations are transient and resolve within 8 weeks $[64,65]$ and can be monitored with mechanosensory measures such as pin prick tests, gentle touch, and two-point discrimination thresholds using linear analogue scales or with patient-reported difficulty speaking and/or eating [66]. A lack of improvement after 3 months indicates that normal function may not be achieved [67], and a referral to an appropriate specialist is recommended for further management, which ranges from conservative to surgical reconstruction. In the unfortunate event that nerve transection is suspected during the surgery, it will require immediate nerve exploration and repair by an experienced surgeon. Besides modifying flap designs, periodontal plastic surgeries such as soft tissue grafts, frenectomies, and vestibuloplasties can be considered to prevent wound dehiscence by achieving a variety of goals such as increasing the flap thickness or keratinised mucosal width, or to reduce the muscle pull from a shallow vestibule or aberrant frenum, but there is 
limited evidence that these techniques prevent wound dehiscence [68].

Wound dehiscence can be classified based the size of the exposure and whether there is presence of exudate, namely small exposures equal or less than 3 $\mathrm{mm}$ without purulent exudate, larger exposures without purulent exudate, and membrane exposure with purulent exudate [69]. According to the included studies in this review, when wound dehiscence occurs, any purulent exudate if present has to be drained and loose mobile graft biomaterial should be removed to facilitate wound closure and healing. The site should subsequently be thoroughly irrigated with chlorhexidine solution. This should be followed up with either twice daily application of chlorhexidine gels $[25,28$, 41] or rinses [41] to reduce plaque accumulation at the wound sites. Weekly reviews [41] should be arranged to nurse the surgical site with the use of cotton tips or swabs soaked with chlorhexidine until the overlying epithelium barrier is formed. While two studies reported the use of adjunctive systemic antibiotics at the time of early exposure $[16,20]$, one must bear in mind the need for judicious prescription of antibiotics and should only be reserved for cases with abscesses formation, purulent exudation, and/or systemic involvement such as fever and malaise. Abscess formation is indicative of possible bacterial contamination and may also occur in the early stages after GBR. Membrane removal, graft curettage, and antibiotic cover should be carried out in such cases [69]. For larger exposures (more than $3 \mathrm{~mm}$ ), the risk of secondary infection may be higher as secondary wound healing will take a longer time, and such defects may require surgical intervention to remove the membrane and flap advancement to re-suture the dehisced flaps together [69]. Late exposures occurring after 3 months from the time of the surgery may also be indicative of an underlying infection. In such cases, antibiotic therapy with close reviews can be considered first [29] before considering the removal of the membrane and any infected graft material [70]. A common antibiotic regimen would be amoxicillin/clavulanic acid (875/125 mg) twice a day for 7 days [29].

In spite of these measures, varying success rates are expected-some cases achieved spontaneous wound coverage $[21,23,25,28,39,41]$, while for others, dehiscence persisted up to 6 months post-surgery, resulting in the need for additional bone augmentation at the re-entry stage $[21,22]$. A re-entry stage at 6 months has been suggested, irrespective of wound dehiscence occurring, unless total graft failure occurs prior to that. A reassessment of the surgical site is then made on whether there is any need for further bone augmentation.

\section{Agreement and disagreement with previous studies}

A recently published systematic review reported an overall soft tissue complication rate of $16.5 \%$ [10], which is similar to the overall incidence proportion of minor complications as reported in this study. However, that review found that the use of a resorbable membrane had a higher weighted complication rate when compared to the use of non-resorbable membranes, contrary to the findings from this study which found no difference in post-surgical complications irrespective of membrane material. Our results also concurred with that of another systematic review which also found similar complication rates between non-resorbable (13.9\%) and resorbable (13.6\%) membranes [9]. The difference in post-surgical complications for non-resorbable membranes between these studies may be attributed to other confounders such as the timing of removal of the membrane, as its delayed removal may have resulted in an increased incidence of post-surgical complications. Furthermore, the types of soft tissue complications and severity of wound dehiscence that occurred in their qualitative analyses, which were not reviewed in the other two systematic reviews, could also play a role in influencing the differences in results. A review also investigated the incidence of donor site complications and noted sensory alterations of the mucosa occurring $18.57 \%$ and $8.19 \%$ of the time when the ramus and symphysis were used as donor sites respectively [71]. The grafts harvested from these donor sites were used as block grafts rather than particulate grafts, which required creating osteotomies with a surgical bur or trephine. While that review did not conduct a meta-analysis, the complication incidence was notably higher from the results of this present review. This could be because older studies from more than 20 years ago were included in that review, and the osteotomy designs might have been more aggressive or extensive. In addition, 3-dimensional imaging (which would be otherwise be mandatory today) might not be available or being used by surgeons then to identify and avoid proximal vital structures, thus leading to higher incidences of neurosensory alterations.

\section{Limitations and recommendations for future research}

In the present review, some caution is advised in interpreting the main findings due to moderate to high heterogeneity among studies when reporting post-surgical complications. The type of study also gave rise to moderate to high heterogeneity when reporting on some of the post-surgical complications (Additional file 3). In addition, post-surgical complications are often not reported in a standardised manner, which gave rise to a reporting bias as shown in the risk of bias analysis. For example, only two studies reported post-surgical complications such as 
extra-oral swelling $[17,38]$, two studies reported postsurgical bleeding [20,34], and one study reported redness as a complication without much elaboration [23]. The negative impact of tobacco smoking on wound healing has been well documented in the literature [72]. However, smoking as a factor could not be isolated for subgroup analysis as most studies did not compare post-surgical complications between smokers and non-smokers. Only one study analysed smoking as a contributory factor and showed that tobacco smoking increased the incidence of postsurgical complications [16]. There was a distinct lack of reporting post-surgical complications at the donor site, and most of the included studies in this review reported only on neurosensory alterations. Furthermore, soft tissue complications such as wound dehiscence and infections at the donor site were often not reported separately and thus precluded a subgroup analysis. This study also quantitatively assessed the complication incidence of neurosensory alterations at donor sites which were used for block grafts only. With the advent of minimally invasive techniques such as shaving or scraping these donor sites to obtain particulate autogenous bone, it would be interesting to evaluate if the post-surgical complications would be markedly reduced when compared to conventional techniques such as autogenous bone harvesting using a surgical bur or trephine.

The heterogeneity in the study designs, the different follow-up periods, and the grafting materials used were the main confounding factors in this review. The ePTFE membranes were the only non-resorbable membranes analysed in this review, but this membrane, especially the titanium-reinforced type, is no longer commercially available. Hence, other nonresorbable membranes such as dense-PTFE membranes should be compared to resorbable membranes in future reviews. There is also a need for studies to report post-surgical complications in a systematic manner. Factors such as the dimensions of the initial and post-surgical ridge width, different grafting materials, assessing complications according to different donor sites, and classifying complications according to early or late complications should be examined in future clinical trials in order to better understand the occurrence of post-surgical complications.

\section{Conclusion}

The increased demand for implants in resorbed or narrow ridges has given rise to various surgical techniques to augment ridges horizontally. The techniques involved in horizontal bone augmentation can potentially result in post-surgical complications such as soft tissue wound dehiscence, membrane exposure, partial or total loss of graft material, and neurosensory alterations. Horizontal GBR is a relatively safe procedure with a low incidence of major complications. Neurosensory alteration is not an uncommon post-surgical complication when autogenous bone is harvested from a donor site and hence caution is advised. Minor complications occur relatively more commonly, with minor wound dehiscence occurring at an incidence proportion of $9.9 \%$ at a site-level. When such complications occur, it requires timely intervention and follow-ups. Exposure of the barrier membrane as a result of wound dehiscence can lead to poorer wound healing and can result in a reduction in the quality and amount of bone regeneration. It is critical that the augmented surgical site remains free of contamination and that the membrane maintains its barrier function in order to allow the underlying bone graft to be populated by osteogenic cells. It is suggested that postsurgical complications should be systematically reported in future clinical trials for research purposes.

\section{Supplementary Information}

Supplementary information accompanies this paper at https://doi.org/10. 1186/s40729-020-00274-y.

Additional file 1. Summary of excluded studies.

Additional file 2. Funnel plots on publication bias.

Additional file 3. Subgroup analysis of post-surgical complications.

\begin{abstract}
Abbreviations
GBR: Guided bone regeneration; Cl: Confidence interval; CENTRAL: Cochrane Central Register of Controlled Trials; MeSH: Medical Subject Headings; PRIS MA: Preferred Reporting Items for Systematic Reviews and Meta-Analyses; ROBINS-I: Risk of Bias in Non-randomized studies_of Interventions; ROB2: Risk-Of-Bias tool 2.0; DBBM: Deproteinised bovine bone mineral; ePTFE: Expanded polytetrafluoroethylene; PTFE: Polytetrafluoroethylene; PRGF: Plasma rich in growth factors
\end{abstract}

\section{Acknowledgements}

None.

\section{Authors' contributions}

JT contributed to the conception, design, and data acquisition and interpretation and drafted and critically revised the manuscript. $J$ contributed to the conception, design, and data acquisition and interpretation and critically revised the manuscript. CL contributed to the statistical analysis and data interpretation. FJH contributed to the conception and design and critically revised the manuscript. All authors gave their final approval and agree to be accountable for all aspects of the work.

\section{Funding}

The authors received no specific funding for this work.

Availability of data and materials

All data are available in the manuscript.

Ethics approval and consent to participate N/A.

Consent for publication

N/A. 


\section{Competing interests}

Rong Hao John Tay, Xiaotong Jacinta Lu, Wei Ming Clement Lai and Jia-Hui Fu declare that they have no competing interests.

\section{Author details}

${ }^{1}$ Discipline of Periodontics, National University Centre for Oral Health Singapore, 9 Lower Kent Ridge Road, Singapore 119085, Singapore. 2Department of Restorative Dentistry, National Dental Centre Singapore, 5 Second Hospital Ave, Singapore 168938, Singapore. ${ }^{3}$ Statistics Unit, National University Centre for Oral Health Singapore, 9 Lower Kent Ridge Road, Singapore 119085, Singapore.

Received: 17 April 2020 Accepted: 27 October 2020 Published online: 26 November 2020

\section{References}

1. Dahlin C, Sennerby L, Lekholm U, Linde A, Nyman S. Generation of new bone around titanium implants using a membrane technique: an experimental study in rabbits. Int J Oral Maxillofac Implants. 1989;4(1):19-25.

2. Wang HL, Boyapati L. "PASS" principles for predictable bone regeneration. Implant Dent. 2006;15(1):8-17.

3. Becker W, Becker BE. Guided tissue regeneration for implants placed into extraction sockets and for implant dehiscences: surgical techniques and case report. Int J Periodontics Restorative Dent. 1990;10(5):376-91.

4. Buser D, Bragger U, Lang NP, Nyman S. Regeneration and enlargement of jaw bone using guided tissue regeneration. Clin Oral Implants Res. 1990; 1(1):22-32.

5. Lang NP, Hammerle CH, Bragger U, Lehmann B, Nyman SR. Guided tissue regeneration in jawbone defects prior to implant placement. Clin Oral Implants Res. 1994;5(2):92-7.

6. Lazzara RJ. Immediate implant placement into extraction sites: surgical and restorative advantages. Int J Periodontics Restorative Dent. 1989;9(5):332-43.

7. Nyman S, Lang NP, Buser D, Bragger U. Bone regeneration adjacent to titanium dental implants using guided tissue regeneration: a report of two cases. Int J Oral Maxillofac Implants. 1990;5(1):9-14

8. Wachtel HC, Langford A, Bernimoulin JP, Reichart P. Guided bone regeneration next to osseointegrated implants in humans. Int J Oral Maxillofac Implants. 1991;6(2):127-35.

9. Thoma DS, Bienz SP, Figuero E, Jung RE, Sanz-Martin I. Efficacy of lateral bone augmentation performed simultaneously with dental implant placement: a systematic review and meta-analysis. J Clin Periodontol. 2019; 46(Suppl 21):257-76

10. Lim G, Lin GH, Monje A, Chan HL, Wang HL. Wound healing complications following guided bone regeneration for ridge augmentation: a systematic review and meta-analysis. Int J Oral Maxillofac Implants. 2018;33(1):41-50.

11. Liberati A, Altman DG, Tetzlaff J, Mulrow C, Gotzsche PC, loannidis JP, et al The PRISMA statement for reporting systematic reviews and meta-analyses of studies that evaluate health care interventions: explanation and elaboration. PLoS Med. 2009;6(7):e1000100.

12. Sterne JA, Hernan MA, Reeves BC, Savovic J, Berkman ND, Viswanathan M et al. ROBINS-l: a tool for assessing risk of bias in non-randomised studies of interventions. BMJ. 2016;355:i4919.

13. Sterne JAC, Savovic J, Page MJ, Elbers RG, Blencowe NS, Boutron I, et al. RoB 2: a revised tool for assessing risk of bias in randomised trials. BMJ. 2019;366: 14898.

14. Barendregt JJ, Doi SA, Lee YY, Norman RE, Vos T. Meta-analysis of prevalence. J Epidemiol Community Health. 2013;67(11):974-8.

15. Begg CB, Mazumdar M. Operating characteristics of a rank correlation test for publication bias. Biometrics. 1994;50(4):1088-101.

16. Sakkas A, Schramm A, Karsten W, Gellrich NC, Wilde F. A clinical study of the outcomes and complications associated with zygomatic buttress block bone graft for limited preimplant augmentation procedures. J Craniomaxillofac Surg. 2016;44(3):249-56.

17. Wessing B, Emmerich $M$, Bozkurt A. Horizontal ridge augmentation with a novel resorbable collagen membrane: a retrospective analysis of 36 consecutive patients. Int J Periodontics Restorative Dent. 2016;36(2): 179-87.

18. Altiparmak N, Akdeniz SS, Bayram B, Gulsever S, Uckan S. Alveolar ridge splitting versus autogenous onlay bone grafting: complications and implant survival rates. Implant Dent. 2017;26(2):284-7.
19. Chappuis V, Cavusoglu Y, Buser D, von Arx T. Lateral ridge augmentation using autogenous block grafts and guided bone regeneration: a 10-year prospective case series study. Clin Implant Dent Relat Res. 2017;19(1):85-96.

20. Gurler G, Delilbasi C, Garip H, Tufekcioglu S. Comparison of alveolar ridge splitting and autogenous onlay bone grafting to enable implant placement in patients with atrophic jaw bones. Saudi Med J. 2017;38(12):1207-12.

21. Naenni N, Schneider D, Jung RE, Husler J, Hammerle CHF, Thoma DS. Randomized clinical study assessing two membranes for guided bone regeneration of peri-implant bone defects: clinical and histological outcomes at 6 months. Clin Oral Implants Res. 2017;28(10):1309-17.

22. Basler T, Naenni N, Schneider D, Hammerle CHF, Jung RE, Thoma DS. Randomized controlled clinical study assessing two membranes for guided bone regeneration of peri-implant bone defects: 3-year results. Clin Oral Implants Res. 2018;29(5):499-507.

23. Wessing B, Urban I, Montero E, Zechner W, Hof M, Alández Chamorro J, et al. A multicenter randomized controlled clinical trial using a new resorbable non-cross-linked collagen membrane for guided bone regeneration at dehisced single implant sites: interim results of a bone augmentation procedure. Clin Oral Implants Res. 2017;28(11):e218-e26.

24. Arunjaroensuk S, Panmekiate S, Pimkhaokham A. The stability of augmented bone between two different membranes used for guided bone regeneration simultaneous with dental implant placement in the esthetic zone. Int J Oral Maxillofac Implants. 2018:33(1):206-16.

25. Meloni SM, Jovanovic SA, Pisano M, De Riu G, Baldoni E, Tallarico M. Onestage horizontal guided bone regeneration with autologous bone, anorganic bovine bone and collagen membranes: follow-up of a prospective study 30 months after loading. Eur J Oral Implantol. 2018;11(1): 89-95.

26. Benic Gl, Eisner BM, Jung RE, Basler T, Schneider D, Hammerle CHF. Hard tissue changes after guided bone regeneration of peri-implant defects comparing block versus particulate bone substitutes: 6-month results of a randomized controlled clinical trial. Clin Oral Implants Res. 2019;30(10):101626.

27. Meloni SM, Jovanovic SA, Urban I, Canullo L, Pisano M, Tallarico M. Horizontal ridge augmentation using GBR with a native collagen membrane and 1:1 ratio of particulated xenograft and autologous bone: a 1-year prospective clinical study. Clin Implant Dent Relat Res. 2017;19(1):38-45.

28. Meloni SM, Jovanovic SA, Urban I, Baldoni E, Pisano M, Tallarico M. Horizontal ridge augmentation using GBR with a native collagen membrane and 1:1 ratio of particulate xenograft and autologous bone: a 3-year after final loading prospective clinical study. Clin Implant Dent Relat Res. 2019; 21(4):669-77.

29. Mendoza-Azpur G, de la Fuente A, Chavez E, Valdivia E, Khouly I. Horizontal ridge augmentation with guided bone regeneration using particulate xenogenic bone substitutes with or without autogenous block grafts: a randomized controlled trial. Clin Implant Dent Relat Res. 2019:21(4):521-30.

30. Solakoglu O, Gotz W, Heydecke G, Schwarzenbach H. Histological and immunohistochemical comparison of two different allogeneic bone grafting materials for alveolar ridge reconstruction: a prospective randomized trial in humans. Clin Implant Dent Relat Res. 2019;21(5):1002-16.

31. GF Tresguerres F, Cortes ARG, Hernandez Vallejo G, Cabrejos-Azama J, Tamimi F, Torres J. Clinical and radiographic outcomes of allogeneic block grafts for maxillary lateral ridge augmentation: a randomized clinical trial. Clin Implant Dent Relat Res. 2019;21(5):1087-1098.

32. Bartols A, Kasprzyk S, Walther W, Korsch M. Lateral alveolar ridge augmentation with autogenous block grafts fixed at a distance versus resorbable Poly-D-L-Lactide foil fixed at a distance: a single-blind, randomized, controlled trial. Clin Oral Implants Res. 2018;29(8):843-54.

33. Deeb GR, Wilson GH, Carrico CK, Zafar U, Laskin DM, Deeb JG. Is the tunnel technique more effective than open augmentation with a titaniumreinforced polytetrafluoroethylene membrane for horizontal ridge augmentation? J Oral Maxillofac Surg. 2016;74(9):1752-6.

34. Ersanli $\mathrm{S}$, Arısan $\mathrm{V}$, Bedeloğlu E. Evaluation of the autogenous bone block transfer for dental implant placement: Symphysal or ramus harvesting? BMC Oral Health. 2016;16:4.

35. Jensen AT, Jensen SS, Worsaae N. Complications related to bone augmentation procedures of localized defects in the alveolar ridge. A retrospective clinical study. Oral Maxillofac Surg. 2016;20(2):115-22.

36. Lee JH, Lee JS, Baek WS, Lim HC, Cha JK, Choi SH, et al. Assessment of dehydrothermally cross-linked collagen membrane for guided bone 
regeneration around peri-implant dehiscence defects: a randomized singleblinded clinical trial. J Periodontal Implant Sci. 2015;45(6):229-37.

37. Merli M, Moscatelli M, Mariotti G, Pagliaro U, Raffaelli E, Nieri M. Comparing membranes and bone substitutes in a one-stage procedure for horizontal bone augmentation. Three-year post-loading results of a double-blind randomised controlled trial. Eur J Oral Implantol. 2018;11(4):441-52.

38. Moslemi N, Khorsand A, Torabi S, Shahnaz A, Soleimani Shayesteh Y, Fekrazad R. Periosteal releasing incision with diode laser in guided bone regeneration procedure: a case series. J Lasers Med Sci. 2016;7(4):259-64.

39. Mordenfeld A, Aludden $\mathrm{H}$, Starch-Jensen T. Lateral ridge augmentation with two different ratios of deproteinized bovine bone and autogenous bone: a 2-year follow-up of a randomized and controlled trial. Clin Implant Dent Relat Res. 2017;19(5):884-94.

40. Li P, Zhu H, Huang D. Autogenous DDM versus Bio-Oss granules in GBR for immediate implantation in periodontal postextraction sites: a prospective clinical study. Clin Implant Dent Relat Res. 2018;20(6):923-8.

41. Zita Gomes R, Paraud Freixas A, Han CH, Bechara S, Tawil I. Alveolar ridge reconstruction with titanium meshes and simultaneous implant placement: a retrospective, multicenter clinical study. Biomed Res Int. 2016;2016:5126838.

42. Sakkas A, loannis K, Winter K, Schramm A, Wilde F. Clinical results of autologous bone augmentation harvested from the mandibular ramus prior to implant placement. An analysis of 104 cases. GMS Interdiscip Plast Reconstr Surg DGPW. 2016;5:Doc21.

43. Qiu L, Yu H. Onlay grafting with bovine bone mineral block for horizontal reconstruction of severely atrophic alveolar ridges in anterior maxillae: a 6year prospective study. J Craniomaxillofac Surg. 2018;46(8):1199-204.

44. Friedmann A, Strietzel FP, Maretzki B, Pitaru S, Bernimoulin JP. Observations on a new collagen barrier membrane in 16 consecutively treated patients. Clinical and histological findings. J Periodontol. 2001;72(11):1616-23.

45. Friedmann A, Strietzel FP, Maretzki B, Pitaru S, Bernimoulin JP. Histological assessment of augmented jaw bone utilizing a new collagen barrier membrane compared to a standard barrier membrane to protect a granular bone substitute material. Clin Oral Implants Res. 2002;13(6):587-94.

46. Friedmann A, Gissel K, Konermann A, Gotz W. Tissue reactions after simultaneous alveolar ridge augmentation with biphasic calcium phosphate and implant insertion--histological and immunohistochemical evaluation in humans. Clin Oral Investig. 2015;19(7):1595-603.

47. Bornstein MM, Bosshardt D, Buser D. Effect of two different bioabsorbable collagen membranes on guided bone regeneration: a comparative histomorphometric study in the dog mandible. J Periodontol. 2007;78(10): 1943-53.

48. Donos N, Kostopoulos L, Karring T. Alveolar ridge augmentation using a resorbable copolymer membrane and autogenous bone grafts. An experimental study in the rat. Clin Oral Implants Res. 2002;13(2):203-13.

49. Garcia J, Dodge A, Luepke P, Wang HL, Kapila Y, Lin GH. Effect of membrane exposure on guided bone regeneration: a systematic review and meta-analysis. Clin Oral Implants Res. 2018;29(3):328-38.

50. Soldatos NK, Stylianou P, Koidou VP, Angelov N, Yukna R, Romanos GE. Limitations and options using resorbable versus nonresorbable membranes for successful guided bone regeneration. Quintessence Int. 2017;48(2):131-47.

51. Jiménez Garcia J, Berghezan S, Caramês JMM, Dard MM, Marques DNS. Effect of cross-linked vs non-cross-linked collagen membranes on bone: a systematic review. J Periodontal Res. 2017;52(6):955-64.

52. McAllister BS, Haghighat K. Bone augmentation techniques. J Periodontol. 2007;78(3):377-96

53. Chao YC, Chang PC, Fu JH, Wang HL, Chan HL. Surgical site assessment for soft tissue management in ridge augmentation procedures. Int J Periodontics Restorative Dent. 2015;35(5):e75-83.

54. Pippi R. Post-surgical clinical monitoring of soft tissue wound healing in periodontal and implant surgery. Int J Med Sci. 2017;14(8):721-8.

55. de Sanctis M, Clementini M. Flap approaches in plastic periodontal and implant surgery: critical elements in design and execution. J Clin Periodontol. 2014:41(Suppl 15):S108-22.

56. Urban IA, Monje A, Lozada J, Wang HL. Principles for vertical ridge augmentation in the atrophic posterior mandible: a technical review. Int $J$ Periodontics Restorative Dent. 2017;37(5):639-45.

57. Burkhardt R, Lang NP. Role of flap tension in primary wound closure of mucoperiosteal flaps: a prospective cohort study. Clin Oral Implants Res. 2010;21(1):50-4
58. Park JC, Kim CS, Choi SH, Cho KS, Chai JK, Jung UW. Flap extension attained by vertical and periosteal-releasing incisions: a prospective cohort study. Clin Oral Implants Res. 2012;23(8):993-8.

59. Fugazzotto PA. Maintenance of soft tissue closure following guided bone regeneration: technical considerations and report of 723 cases. J Periodontol. 1999;70(9):1085-97.

60. Fugazzotto PA. Maintaining primary closure after guided bone regeneration procedures: introduction of a new flap design and preliminary results. J Periodontol. 2006;77(8):1452-7.

61. Greenstein G, Greenstein B, Cavallaro J, Elian N, Tarnow D. Flap advancement: practical techniques to attain tension-free primary closure. Periodontol. 2009;80(1):4-15

62. Urban IA, Monje A, Nevins M, Nevins ML, Lozada JL, Wang HL. Surgical management of significant maxillary anterior vertical ridge defects. Int J Periodontics Restorative Dent. 2016;36(3):329-37.

63. Urban IA, Monje A, Wang HL, Lozada J, Gerber G, Baksa G. Mandibular regional anatomical landmarks and clinical implications for ridge augmentation. Int J Periodontics Restorative Dent. 2017;37(3):347-53.

64. Smith MH, Lung KE. Nerve injuries after dental injection: a review of the literature. J Can Dent Assoc. 2006;72(6):559-64.

65. Mason DA. Lingual nerve damage following lower third molar surgery. Int J Oral Maxillofac Surg. 1988;17(5):290-4

66. Kushnerev E, Yates JM. Evidence-based outcomes following inferior alveolar and lingual nerve injury and repair: a systematic review. J Oral Rehabil. 2015; 42(10):786-802.

67. Renton T. Oral surgery: part 4. Minimising and managing nerve injuries and other complications. Br Dent J. 2013;215(8):393-9.

68. Burkhardt R, Lang NP. Fundamental principles in periodontal plastic surgery and mucosal augmentation--a narrative review. J Clin Periodontol. 2014, 41(Suppl 15):S98-107.

69. Fontana F, Maschera E, Rocchietta I, Simion M. Clinical classification of complications in guided bone regeneration procedures by means of a nonresorbable membrane. Int J Periodontics Restorative Dent. 2011;31(3): 265-73

70. Cucchi A, Chierico A, Fontana F, Mazzocco F, Cinquegrana C, Belleggia F, et al. Statements and Recommendations for Guided Bone Regeneration: Consensus Report of the Guided Bone Regeneration Symposium Held in Bologna, October 15 to 16, 2016. Implant Dent. 2019;28(4):388-99.

71. Reininger D, Cobo-Vazquez C, Monteserin-Matesanz M, Lopez-Quiles J. Complications in the use of the mandibular body, ramus and symphysis as donor sites in bone graft surgery. A systematic review. Med Oral Patol Oral Cir Bucal. 2016;21(2):e241-9.

72. Sorensen LT. Wound healing and infection in surgery: the pathophysiological impact of smoking, smoking cessation, and nicotine replacement therapy: a systematic review. Ann Surg. 2012;255(6):1069-79.

\section{Publisher's Note}

Springer Nature remains neutral with regard to jurisdictional claims in published maps and institutional affiliations.

\section{Submit your manuscript to a SpringerOpen ${ }^{\circ}$ journal and benefit from:}

- Convenient online submission

- Rigorous peer review

- Open access: articles freely available online

- High visibility within the field

- Retaining the copyright to your article

Submit your next manuscript at $>$ springeropen.com 